\title{
Structure and event, networks and nodes in human geography: the 1960s revisited
}

\author{
U. Strohmayer \\ School of Geography \& Archaeology, NUI Galway, Ireland \\ Correspondence to: U. Strohmayer (ulf.strohmayer@nuigalway.ie)
}

Received: 9 November 2012 - Revised: 25 January 2013 - Accepted: 5 February 2013 - Published: 30 May 2013

\begin{abstract}
In search of transnational scholarship and languages within human geography, the so-called "Quantitative Revolution" of the 1960s arguably holds considerable pride of place. More than previous innovations within geography, which were largely bounded within (and by) national intellectual traditions, the innovate practices associated with the 1960s arguably hold a key to understanding how intellectual traditions become shared traditions and as such enrich both national and international research practices. The present paper uses insights gleaned from the 1960s in the context of a geography still oscillating between "structural-" and "eventdriven" forms of explanation in an attempt better to understand pronounced (if historically uneven) interweavings of national traditions that shape discourses and practices in human geography across the globe. Part of this analysis will focus on the importance of structures and careers in the making of such traditions, thereby contextualising the widely shared notion of an "Anglo-Saxon hegemony" currently prevailing in human geographical theoretically informed practices. Throughout, the paper focuses on the task of editing a journal like Geographica Helvetica as a transnational journal interested in bridging traditions formed by particular languages across Europe and beyond.
\end{abstract}

\section{Introduction}

This paper was written in an attempt to place the publication of an academic journal in the wider context of debates, histories and concerns at the heart of geography as an academic discipline. On the surface, then, the paper is merely re-affirming a link that is well established in academic geography and beyond: the way we debate, the language that we use to communicate academic positions clearly has a bearing on the knowledge we create. What we accept as being "epistemologically sound" acquires such legitimacy in the context of prior arguments, most of which are encountered at conferences, in books and through journals; the way these latter are organised, structured and maintained thus has direct consequences for the knowledge propagated therein. As such, the role and function of Geographica Helvetica is no different from other academic journals; where it differs is in the lack of both a unifying language and an a priori, binding tradition: the position of both Switzerland and its main geographical journal at a multi-linguistic crossroad between different traditions makes the formulation of an editorial mission and associated editorial practices difficult. At the same time, this "lack" holds the promise of a different kind of journal, a journal that does not so much dwell on accepted (and thus taken-for-granted) traditions but actively seeks to explore the common ground or the differences between diverse traditions instead. And if the metaphor of the "crossroad" is an apt one for the position of the journal, the question effectively becomes how best to dwell on and develop such a place without, to use a well-worn apocryphal history, falling prey to blues musician Robert Johnson's curse and having to sell our respective souls to some devil for us to accomplish something new. Is there, in other words, a way of successfully negotiating between different academic traditions? What are the epistemological problems we encounter while attempting creatively to answer this question? This paper asserts that any epistemologically sound answer - an answer that does not veer into either idealism or the elevation of one tradition over another - must formulate a relationship between structural and non-structural properties as a key element of 
any tradition, academic or otherwise. Historically and epistemologically, such "properties" come in many shapes and guises, but whatever their precise configuration, they legitimise what can be recognised as knowledge within a community of scholars. By way of analogy, it may be helpful to think of the relationship between "structure" and "nonstructure" (or "event", as philosophical custom would have it), as akin to the reciprocal rapport that emerges between a network and the individual nodes and movements that are facilitated by its existence. Inversely (and to warrant the use of the adjective "reciprocal"), being composed of (or even necessitated by) events, "structures" are never absolute in an a priori sense of the word, all the while being encountered historically as if they pre-existed events. Hence, the historically contingent relationship between structures and events: being human thus implies not to have a choice in this particular context: we are, as Martin Heidegger famously phrased this primary fact, "thrown" (geworfen) into what already exists chief amongst which is the structure of language we use to communicate (Heidegger, 1927, Sect. 38).

As a fundamental structure, language in turn communicates by embedding structures in the form of its operations: from simple sentence structures to ordering principles or "grammar", from the scaling of its processes and concepts to anthropologically "raw" givens, it is through the creation or adoption of structures that we converse and create knowledge by bestowing meaning to events. Or so we thought, following a line of reasoning modelled by structuralists like Claude Lévi-Strauss (1963). In what follows, the paper will analyse to what extent, if at all, the publication of a journal like Geographica Helvetica can continue to posit itself as one such functioning structure and employ structural devices to create, communicate and debate geographical knowledge in the twenty-first century. To this end, the paper will first introduce the epistemological dimension central to its argument before applying its logic to a well-rehearsed segment in the history of geographic thought, namely the so-called "Quantitative Revolution". The final part of the paper will in turn employ these ideas and histories in an attempt to reconsider practices surrounding the publication of an academic journal. Throughout, the paper will retain its adopted anchorage by focussing on possible editorial practices for Geographica Helvetica without speaking for the newly assembled editorial team.

\section{Structure and event in geography}

The context for contemporary epistemological debates and related editorial work was arguably set some $47 \mathrm{yr}$ ago when a still-young French philosopher single-handedly closed the book on accepted structuralist manners of thinking, while opening something new that in time could no longer as readily be called a "book" (Derrida, 2005). On 21 October 1966, as part of a conference on "The Languages of Criticism and the Sciences of Man" organised at the Humanities Center of the Johns Hopkins University in Baltimore, Jacques Derrida delivered what was to become his entry into the world of philosophical discourse. The signature of this talk, the legacy of "La structure, le signe et le jeu dans le discours des sciences humaines" is arguably still with us today, if perhaps more so in its 1976 translated form entitled "Structure, Sign and Play in the Discourse of the Human Sciences" included in the English edition of Writing and Difference (Derrida, 2001).

To begin an intervention in geographical discourse with an allusion to the work of a philosopher may seem odd: for many readers acquainted with Derrida's work, such a reference today may furthermore seem like a souvenir dated from a seemingly distant galaxy designed to invite acts of reminiscing and nostalgia. And yet, neither of these responses is intended nor fitting for Derrida's intervention still sets the tone, lays the marker and embodies the challenge that any thinking of "structure" will have to address lest it run the risk of being metaphysically idealist and thus implicitly circular or self-referential in orientation. And "structures" there are: Geographica Helvetica clearly is a structure of sorts furnishing us with a means to communicate, to unite, even to rally behind. And yet, given the plurality of languages and traditions that find a home in the journal, the notion of a unified structure is clearly misleading, thus forming a "special case", an opportunity even, amongst geographical journals. We shall return to questions posed by multiple traditions and languages later in this paper; at present, suffice it to emphasise the importance of structure and "structural traits" or "grammar" for the construction, legtimisation and dissemination of knowledge. One need not have read Derrida to appreciate the structural importance of language as a condition of possibility for knowledge.

Historically, the implicit boundaries erected by such different structures - the different "houses of being" a geographer, as a Heideggerian may note (Gould, 1999; see Heidegger, 1949:5) - mattered little in practice for as long as geography remained fairly comfortable within the respective houses that emerged. This describes to a considerable extent the state of affairs surrounding geographic scholarship until the end of the Second World War: with notable exceptions, most geographers were largely content with the resulting, highly nationalised intellectual landscapes since the power derived from being useful and thereby capable of maintaining emerging and subsequently existing academic structures within nationally defines discourses and customs suited most of our predecessors (Wardenga, 2006:140).

Beyond this all-too-familiar world still shaped by its 19th century academic origins, colonial practices and their accompanying university structures, the choice facing geographers today seems to be of a different nature: we can either cling to the familiar and rest comfortably lodged within whichever "house" we happen to grow up in or engage in arduous and complex acts of translation between different traditions. 
Notwithstanding the fact that these linguistically formed houses of geographic knowledge survive in the names and languages adopted by many geographical "flagship" journals (and Geographical Helvetica is not an exception), the first option, the furnishing of these houses along existing national traditions, seems, if nothing else, rather boring and is furthermore in practice often superseded by conceptual developments emanating from within an increasingly hegemonic Anglo-Saxon "world geography" (again including $G e$ ographical Helvetica alongside the author of the present paper). Translation, on the other hand, is bound up within the old hermeneutic circle that positions each one of us within a particular linguistic tradition, a position from which to engage with translating from or into "another" language. "Being Swiss" affords some of us a special advantage in this respect by more openly embracing the acquisition of multilinguistic competences from an early stage in life, but inevitably even Swiss people have a limited choice of languages to translate from and into. Finite human beings that we are, linguistic competence only ever extends so far before we are no longer "at home" in the traditions we seek to render comprehensible or reconcile. Even the art of moving between two clearly defined structures all too often faces an infinite regress of sorts: to determine what, if any, common ground exists between, say, the French notion of paysage and the German Landschaft, we either enter into the endless regress of qualifications of the "not quite" or "yes, but" variant or we accept a third language, a third structure, as a commonly agreed vanishing point or grammar. Unless, in practice, we all speak "English" - as indeed many of us do, leaving us in a position not ultimately different from the one described before (Harris, 2010). Note that this "third language" could well be a politically derived compromise, a kind of "settlement", a commonly agreed heuristic device - as the use of "English" is all too often characterised by those fluent with its finer differentiations.

It is the absence or political undesirability of such a "third language" or meta-structure that creates initial problems, or rather the fact that whatever "third" language is adopted remains a "first" language for some. In this, Switzerland is perhaps structurally more akin to the European Union than we dare admit within the Confoederatio Helvetica in that the statistical dominance of one language (German in Switzerland; English in the EU) forces all kinds of compromises and strategic meanderings; in contrast to its Swiss counterpart, however, the EU does not demand of its citizens fluency in more than one tradition, language or "grammar" or structure. A journal like Geographica Helvetica could thus become a truly European project were it to embrace its position at this particular "transcultural" crossroad; even then, however, the epistemological problems alluded to earlier on would not be solved but moved sideways instead; even assuming we could become conversant and thus "at home" within this new, ostensible more inclusive structure, this particular compromise would still be a European, indeed a largely colonial one, leaving those not part of a historically pre-determined set of structures with little choice but to master one of the "accepted" ways of conversing before being invited to contribute. Indeed, as structures need to be shared for them to acquire a structuring ability, publishing a paper in, say, Hindi in Geographica Helvetica might furnish a philosophical, humanitarian or political point, but would scarcely serve many other purposes.

But adherence to and translation between existing structures are not the only options in front of us today. Derrida, as readers may be aware or willing to recall, was well attentive to problems surrounding both mono-and pluri-linguistic discursive structures. When in "Structure, Sign and Play", he famously juxtaposed the notion of "structure" against what he called "the event", with the former possessing a "centre", and the latter being its own centre, he implicitly posited a relationship that we ought to analyse in some more detail. In what follows, this paper pursues such an analysis in the context and service of an academic journal; the argument, which will be made more empirically resonant through references to a structure or grammar that is widely shared within the geographic community, will posit our understanding of this relationship as central to any editorial (or "structural") undertaking - something we shall return to throughout this paper.

It may be helpful initially to realise that the relationship between "structure" and "event" can be conceptualised differently from the way the present paper engaged with it to this point. Unlike the analogy used further up, likening "structure" to a network, say, of roads and "events" to individual movements thereon and thus starting from an in-built causal relationship between the two, "structure" and "event" are often linked in less straightforward, context-dependant manners. Two such modes in particular suggest themselves, depending crucially on our understanding of "the event". On the one hand, "events" are often thought and acknowledged as unexpected exceptions to whatever we came to anticipate with relationship to a given structure: unanticipated categorical "pollution", disruptive practices, outliers in statistics, non-sensical linguistic utterances or more generally that which a present structure or form of knowledge could not encompass. On the other hand, "the event" comes to mark a philosophical sine qua non, the Heideggerian "something" or "being", rather than "nothing" (Heidegger, 1959:7-8), a kind of Ur-grund or condition of possibility for any thought, knowledge and science. (A third kind of event, the "event" as a "special" occasion of the "Olympic" or "wedding" variant need not concern us here as arguably it is not epistemologically relevant.) Arguably, incorporating the event as "exception" or "pollutant" into whatever knowledge we produce has always been a key moment in any science and has been a key feature in methodologically inclined theories of science (see chapter 1 in Abler et al., 1972 for a splendid geographical exposition of this view), while the latter, the event as condition of possibility, has only recently entered into our debates (Jones, 2009; Anderson and Wylie, 2009; Dewsbury, 
2010; Woodward, 2010). Faced with the event as a challenge to structures, geographers responded in the main by scaling their claims to knowledge to incorporate - and thus mute exceptions. "Scalable", the event became part of a hierarchical structure and thus accessible to knowledge through the elimination of any distance separating event from structure, effectively making events structurally sound elements in the production of science. Alternatively, where the construction of a link to pre-exisiting structures through the invocation of scale proved to be politically undesirable or theoretically impossible, events begat their own scale and became capable of expressing themselves, of incorporating, working out structures of their own, a kind of "immanent grammar" that constantly defines and re-defines its structural properties by entering into multiple relationships with other events.

However, the problem with either of these solutions is that, functionally speaking, the event ceases to be an event and becomes a (or its own) structure or structural component, a grammar deployed to understand the world, or in the words of Abler, Adams and Gould, a

"single class $[\ldots]$ which embraces all possible occurrences of any sort and enables us to talk about what we do to them" (1972:5),

and as such it becomes yet again vulnerable to the kind of deconstructive labour that can attach to traditions or unifying grammars where and if it is pursued. In other words, as structure (albeit at a reduced scale), "events" again invite the recognition of exceptions, of that which cannot be encompassed by their epistemic reach. Here events are always already made to correspond to the structures or structural properties that will make them intelligible; it is as such that they can become, by way of example, "experiences" (Abler et al., 1972:6) rather than remain mysterious or otherwise beyond language. "Scale", or rather the stability afforded by the stable order expressed by scale, here allows for an organic link between event and structure that appears to satisfy our need to know.

We will need to ask ourselves whether there can be an alternative in which the relation between "structure" and "event" is neither a hierarchical nor a self-insulating one, but before we do so, let us re-enter into the history of geographic thought, let us - broadly speaking - apply the above train of thought to matters in hand. In geography, those now working with a Derridaen (or more broadly: a post-structuralist) inclination and thus aware of the need to rethink the relationships between "structure" and "event" appear to have opted for one of the two solutions described so far. Witness what happened within geographic discourses and debates since Derrida published his momentous intervention. If once we thought of ourselves as capable of expressing geographic knowledge and scholarship in a universal language (even if the universal language in question happened to be our own "national" one), our fall from that particular grace uncannily followed the disciplinary logic outlined above to a fault.
Faced with a near-universal language towards the end of the 1960s, a language itself borne of the critical interrogation of earlier and allegedly idiographic structures, geographers increasingly sought to engage with "events" (or with that which did not fit) in a host of attempts at scaling knowledge or at uncovering an "immanent structure" of one kind or another.

The near-universal language of the 1960s was, of course, none other than the language of mathematics structured largely by a grammar borrowed from inferential statistics. The earliest critiques issued against this ideal of a monolingual geography are well known and have become part of our collective memory: on the one hand, we had the humanist responses of the "statistics don't bleed" variant (Livingston, 1992:304), while on the other hand Marxists reminded us - and continue to do so - of the importance attaching to wider material contexts shaping the categories we deploy (Harvey, 1973). Agency and structure, as it were, came to haunt the categories born of the 1960s' attempt at rendering "translation" an unwelcome, indeed an unnecessary, activity amongst geographers. People mattered, as did the material world and the categories born of its struggles and interventions. Never mind the fact that subsequent developments in turn questioned the stability of the "agency" and "structure" differentiation (Hannah and Strohmayer, 1991), over time the two attempts at taming the event more or less merged following the realisation that the activity of "scaling", while linking "structure" and "event" internally, did not provide an in-built means of relating an emergent structure to anything else (see Marston et al., 2005; Jones III et al., 2007), thus yet again creating exceptions and proliferating events. The eventual result of such pursuits has been the creation of the present, highly nominalist landscape of geographical scholarship - even within nominally homogenous linguistic traditions: although most colleagues would deny it, we have effectively entered a world of research and scholarship where "anything goes" as long as two key criteria are fulfilled: (1) a sufficient amount of labour can demonstrably attach to the categories we deploy, and (2) such labour is used primarily in the service of qualifying a previously accepted category or form of knowledge. If "nominalism" is the stubborn belief in the primacy of particular over general forms of knowledge (effectively mirroring the first relationship between structure and event unpacked in this paper), the pronounced reduction in the scale of geographic explanatory ambitions since at least the late 1980s would indeed appear to fit the description, with virtually every and all geographically relevant phenomena nowadays requiring potentially infinite descriptions (and thus, a cynic may add, justifying the publication of an insight in more than one journal).

But let us make no mistake: however qualified, small or ultimately unique geographical knowledge is held to be or represented, for it to be intelligible it has to conform to a grammar of sorts. In other words, it has to adhere to a structurally similar logic to the one it set out to criticise, incorporating hidden assumptions, circular forms of reasoning and the 
maintenance of boundaries stabilising - however temporarily - its claim to being an event. In short then, the classical Derridaen scenario bites even if we aim to part company with a hegemonic "structural logic" of old and attempt to be more modest in the presentation of our scholarship and research. Neither does the fact, so often invoked in epistemological debates, that we have to retain a semblance of structure for the event to become intelligible serve as a way forward: as a category - for any structured event becomes a category - the event is bound up in the same logic and necessities that rendered structures vulnerable some $47 \mathrm{yr}$ ago. Likewise, having travelled this far only to realise that we cannot escape from the grasp of structure may render the journey important, but it does not justify celebrating wherever we end up as a necessary place of arrival. As Dixon and Jones III reminded us some fifteen years ago,

"[t]he category, as well as the boundary on which it depends, appears as a 'natural' part of social life precisely through its necessity; but these should not be conflated. There is nothing natural about how categories are constructed, deployed, and confronted [...]." (Dixon and Jones, 1998:253)

Phrased differently, the epistemological impossibility not to approach "events" but in a structurally mannered mode should not tempt us to celebrate any "other" to structure - be that the free flow of linguistic experimentation (Doel, 1996), hybrid forms of geographical knowledge (Whatmore, 2002), "affects" (Anderson, 2006) or "non-repesentational" forms of geography more generally (Thrift, 2007) - as if this socially constructed "other" remained immune to the challenges of a uniform language. " $[\mathrm{H}]$ owever radical our social constructionism in principle", Matthew Hannah reminded us some ten years ago, "none of us can escape treating some things, states of affairs, discursive conventions, etc, as though they are stable, 'true', reliable" (Hannah, 2001:518).

The relevance of this train of thought for those practices associated with editing and publishing a journal may not be immediately obvious. The earlier allusion to the importance of "grammar" apart, does an engagement with Derrida and his ideas have any relevance for editorial work in the context of a Geographica Helvetica fit for the 21st century? In a quite direct way, the relationship between "structure" and "event" and the manners in which we conceptualise these two is at the heart of such an endeavour for the simple reason that it is through this relationship that some traditions become accepted, normalised even, while others are accorded an "exceptional" status at best. If, as this paper is arguing, recent attempts at rendering "exceptions" "normal" do not fundamentally alter the geometry of this epistemic equation, we cannot then derive a leitmotif for further editorial or broadly academic practices by adopting a non-structural stance - or position ourselves between structures without presuming structural properties for such a stance. Thus, and assuming the above brief analysis of geographic thought and practice res- onates with readers of this paper, neither "scaling" nor the notion of an immanent structure will ultimately gain us any epistemological advantage since both responses remain vulnerable to exactly the same kind of deconstructive critique that has motivated geographical theory during the last three or four decades. If editorial work requires a guiding beacon other than that of the policeman within secure linguistic traditions, where should that central idea come from? Anything goes? Nourishing a plurality of discourses that defies the notion of any "policeman" beyond rather ill-defined ideas of academic "rigour" or "ethics"? But then, is the rigour demanded of the event the same as the one called for by structures?

An informed guess is that we have been here before, if arguably at the opposite end of a spectrum that extends between "structure" and "event". If the so-called quantitative revolution of the 1950s and 60s created a short-lived monolithic structure that predated all of our present discussion, a structure born of mathematics and applied in the form of nondescriptive statistics, it did so in full awareness of the precise problems that a journal like Geographical Helvetica will have to address: problems associated with traditions, languages and associative and supportive networks and nodes. This paper will briefly address these three problems before drawing conclusions from my analysis and charting a possible future for the journal.

\section{3 "Quantitative" geographies revisited}

In revisiting briefly the late 1950s and early to mid-1960s, this paper does not intend to do justice to the many different motifs or contexts that have been shaping what has become known as the "Quantitative Revolution". Nor does it seek to unravel once again the often complex underlying logic of mathematical modelling that was to become the driving force for the "movement". Instead of focussing on "the universal language of mathematics" (Garrison, 1956:428, as citied by Barnes, 2001:417), the paper will ask how the Quantitative Revolution sought to reconcile the tension between "structure" and "event" in an attempt to build a geography that would not require translation yet be equally accessible to all practicing geographers, irrespective of the traditions to which they belonged. Phrased in these terms it should become clear that the Quantitative Revolution was not a singular movement; in fact, it is the lack of a singularity that will be the main focus of the remainder of this paper.

Let us turn to "traditions", the first of our structural headings. Contrary to common belief, the Quantitative Revolution did not dispense with these but in fact used "tradition" to position its own claims strategically (but see Barnes, 2004). Like any "revolution" it was thus necessarily partially parasitical upon that which it sought to replace (or towards that which it sought to legitimise by inclusion into a new genealogy, a path already pursued by none other than Walter 
Christaller in his reference to the work of Johann Georg Kohl in the opening pages of his "Central Places" (1966:8). The infamous debate between Fred Schaeffer and Richard Hartshorne - and here we have to use inverted commas around the term "debate" since the untimely passing away of Fred Schaeffer before the debate took place but after the acceptance of his seminal paper on "Exceptionalism in Geography" (Schaeffer, 1953; see also Bunge, 1979) - set the tone in this respect, a tone much retained in the early stages of the "revolution" before new categories, as well as processes, methods and ideas, took over and populated the newly emergent realm of "quantitative analysis". The manner in which this debate is taught to undergraduate classes often deploys the notion of "tradition" in an adjectival manner, leaving the one side of the "debate" (Hartshorne's) to fight demons of the past while the other (Schaeffer's) strove to break new ground. The actual debate, however, was much more symmetrical in its positionings, with both sides constructing legitimacy through a selective invocation of actual antecedents and implied genealogies. The novelty of a uniform structure, in other words, did not claim to be constructed ex nihilo but was every bit as "traditional" as its more descriptive counterpart arguing for the importance of a holistic approach based in particular geographical landscapes. Hiding this fact from public view allowed for an implied "tainting" of older, "idiographic" forms of geographical knowledge with a coat of "exceptionalism", while on the flip side "nomothetic" epistemologies emerged as progressive, forward looking, indeed radically chic during the 1950s and throughout the 1960s. Combined with the epistemological raison d'être of the debate - the differentiation between a universal structural approach on the one hand and an event-infested, particular one on the other - such elimination of tradition helped to accentuate the singularity of "structure" even more and made it appear to be independent of the context from which it emerged.

Indicative of this process (and of particular importance in our present context) was the culmination of the revolutionary process in the founding of the new journal Geographical Analysis in the otherwise also momentous year 1968. One could easily construe this move as setting a strategic editorial tone for decades to come, using the creation of a new publication outlet to secure, populate and maintain a novel form of geographical practice. The proliferation of geographical journals in our own lifetime - nowadays including journals devoted to, say, Tourism Geographies (founded in 1998), Children's Geographies (founded in 2002), and Mobilities (founded in 2005), which sit alongside the traditional "national" flagship journals like the Annals of the Association of American Geographers (founded in 1910), Transactions of the Institute of British Geographers (founded in 1935) or the Geographica Helvetica (founded in 1946) - denotes an ever-increasing compartmentalisation of geographic knowledge even where the stated aim of a journal and its associated personnel is universal in ambition, tone and practice. In the present moment, this trend is furthermore accentuated by the proliferation of blogs and related novel forms of disseminating geographical scholarship, perhaps rendering the creation of a journal devoted to "Geographies of Affect" slightly less urgent and, quite possibly, likely. At any rate, the outcome of this process has been and continues to be an insulation of particular forms of geographic research from a more general scrutiny. De facto, the arrival of the Quantitative Revolution in the safe haven of a journal devoted to propagating its claims thus set in motion a new structural legacy that is still very much alive. But then, does this matter to us today? Do we as geographers still identify with journals to the extent that a previous generation did? Antipode and similar cause-driven journals apart, we could venture the guess that most geographers search thematically for the papers that interest them, using Google Scholar, Elsevier's geobase or similar portals to search across different journals for what may or may not be of interest at a given moment in research time. Note that often such searches do not stop at some nonspecific outer disciplinary boundary, especially if the discipline in question is itself a rather ill-defined one like geography. Should Geographica Helvetica respond to these novel trends and possibilities? Should it dispense with "traditions" to allow for the emergence of a new argumentative field? If so, how?

Related to this is the question of language. As many have noted, the notion of a "quantitative" revolution as possessing a "quantitative" language of its own is a rather misleading signifier since quantitative forms of geography have been part and parcel of geographical knowledge since its inception (see Philo, 1998:194). Equally, as Barnes and Hannah reminded us a decade ago, are "numbers [...] woven into the very fabric of modernity. By disregarding them, we disregard large chunks of what we try to understand" (2001:379). What the 1950s and 1960s added to this was a new grammar consisting of regression analyses and coefficients derived from statistics, used not merely to describe reality but to impart an underlying glue to its existence. Armed with this glue, reality became predictably (and deliberately) normal around a spread of probable distributions. The result both narrowed the scope and ambitions of what "quantitative" implied in geographical research and method (Gould, 1969; also Wilson, 1989) as it legitimised research building from an "epistemology of the grid" (Dixon and Jones III, 1998:251) upward. The glue was thus fabricated with the help of a particular structure, a digital language that differentiated primarily between "presences" and "absences", between " 0 " and " 1 ", while maintaining, policing the boundaries between these two with the help of a belief in binary and essentially linear (and thus predictable) ontologies - which have since become the focus of Gunnar Olsson and Marcus Doel's writings (Olsson, 1980, 1991; Doel, 2001). Crucially, as Matthew Hannah maintained in his work on the US and German censuses (Hannah, 2001, 2010), the constitution in turn of the relationship between presence and absence in the language of the Quantitative Revolution itself never escaped from the 
clutches of non-immanent interferences, especially in processes of category formation and of sampling.

Here again the aspirations of the Quantitative Revolution may seem to have been unique in their insistence on the deployment of a universally accessible structure-cumgrammar; after all, regression analyses would not seem to require much by way of contextual awareness, caveats and qualifications. And yet, they did and continue to require proficiency in a particular style of reasoning that was neither less nor more circular in orientation than alternative traditions, including the Hartshornian one ostensibly used as a negative template by the revolutionaries. As Trevor Barnes observed in his illuminating Latourian paper on the Quantitative Revolution in Progress in Human Geography some years ago,

"Papers such as Berry and Garrison's (1958 entitled 'The functional bases of the central place hierarchy'), through the statistical style they prosecute, initiate within the discipline new candidates for truth and falsehood never contemplated before. The criteria of truth and falsehood they deploy, and embodied in statistical coefficients like chi square and regression found in their paper, is given only by the statistical style on which they draw, having no purchase outside of it" (2004:570).

"The structurality of structure", to invoke our Derridaen lodestar yet again (Derrida, 2001:351-352), is thus an externally borrowed one and not supported by anything timeless or universal; not surprising therefore (as per our earlier discussion in this paper) that events can intervene - like those material nodes with their respective infrastructures, personal connections, support mechanisms and technologies, all constitutive in the construction and maintenance not so much of truth but of trust. Time and again, the question posed in this paper - how to relate structure to events - emerged in plain sight and threatened to destabilise the workings of structure because it too required qualifications, caveats, locally specific arrangements and the like. In answering such questions (where and if they emerged), it must have helped that virtually all "space cadets" (see Barnes, 2004:572) were able to contextualise in turn their ambitions, goals and desires in the medium of English, no matter whether they were of German, Swiss, Swedish or some other descent or origin. The dominance of Germanic languages in the annals of the Quantitative Revolution may be accidental; its contribution to an atmosphere of mutual recognition and trust that would in turn support and maintain alliances surely is not.

Finally, then, what about those networks and nodes announced in the title of the present paper? To an extent, these are the direct outcome of those structuring devices already discussed, although, admittedly, the personal and institutional history of the Quantitative Revolution can serve as an additional reminder that like other revolutions, this too"was place-based" (Barnes, 2004:566). The story has been told before and is perhaps most succinctly captured in Peter Taylor's famous 1976 "Quantgeog airlines flight path" established between six key institutional nodes - the Universities of Washington, Iowa, Michigan, Chicago, Bristol and Lund (see Taylor, 1977:15) - and motivated, populated and developed by what became a rather well-known set of geographical revolutionaries whose names now fill textbooks on the history of geographic thought (for an overview see Strohmayer and Gould, 2003). Crucially, both individuals and institutions, networks and nodes, form events in the history of the Quantitative Revolution: they both contradict the time- and spatial logic of the movement while being irreducibly connected to them. Small wonder then, that these have been exorcised from key texts of the "Quantitative Revolution": when publishing what was to become a seminal text in the annals of quantitative geography in 1933, Walter Christaller still made reference to Central places in Southern Germany (1966); compiling an index to the forth volume of Models in Geography (Chorley and Haggett, 1969) some 34 yr later, David Stoddard assuredly informed his readers that since "places" did not matter, he saw no reason to list "the many incidental references to place-names in the text" (670; the original book was published in 1967). The abstraction introduced by the notion of "place-names" is a prime example of the subduction of events to a structural logic of sorts, "submerging" something potentially disruptive to fit into - in fact, to become one with - a larger structure.

The irony is tangible: the very movement in geography that accorded points and lines a central structural position in its epistemology - who can forget the beauty of Peter Haggett's pedagogical attempt at rendering these accessible to students in the first chapter of his "Geography. A modern synthesis" entitled "On the beach" (Haggett, 1972) - can be haunted by events composed of specific nodes and particular networks, explicitly expunged from geography in the first sentence of Torsten Hägerstrand's 1953 Swedish original of Innovation diffusion as a spatial process ("This study is not concerned with the analysis of a specific geographic area; its object is to deal with the diffusion of innovations as a spatial process", 1967:1). A "haunting" that has recently been addressed within the discipline by a raft of papers (Barnes, 2009; Wyly, 2009; prominent earlier such attempts included inter alia Marchand, 1974; Pickles, 1995; Philo, 1998; Flowerdew, 1998 and Sheppard, 2001) often culminating in statements like the following:

"Quantitative geography, when integrated with a critical sensibility and used appropriately, can be a powerful tool for fostering progressive social and political change" (Kwan and Schwanen, 2009:284).

The target of these and related papers is often a perceived binary differentiation between "qualitative" and "quantitative" epistemologies. Therefore, and not surprisingly, the solution offered has everything in common with earlier attempts at prying open the "agency" and "structure" binary - and we 
may well fear a re-run of potentially endless qualifications to litter the pages of geographical journals in years to come, aiming to establish just how much and what forms of "sensibility" are required or what precise practice would entail an "appropriate use" of quantitative approaches. Plus ça change, plus c'est la meme chose - domesticating "the event" can indeed take many forms (see Strohmayer, 1998).

\section{Conclusions}

To conclude is to maintain that the problems underlying a single language are not distinct from those characterising non-singular or plural languages, is to insist on the primacy of epistemology (or representation) over and against ontology (or reality; see Dixon and Jones, 1998:251): the way we relate "structures" to "events" and vice versa matters because it is through this relationship that we create, re-create and draw upon specific grammars that render the world intelligible. The fact that epistemologically "structure" and "event" are indistinguishable (as the present paper has argued throughout) makes it more difficult to "pitch" a determined editorial line for any academic journal at the beginning of the twenty-first century. In this, Geographica Helvetica is not an exception - but may well become the first journal openly to embrace the consequences by opting to focus neither on "events" (as expressed, for instance, by a possible "Swiss" exceptionalism) nor on "structures" (by adopting, say, any of the accepted geographical sub-disciplines); if anything, the conscious positioning of the journal at the crossroads of geographical traditions should alert both its editors and readers to the enduring presence of an instable oscillation between structure(s) and event(s). After all, why fear and aim to eliminate what is inevitable?

So, again, where does this admittedly rough assessment of the possibility of a uniform language leave us? Not with the dichotomy we started out from: the duality between a uniform language on the one hand and the need for translation on the other. Instead, we face a scaled impossibility that throws us right back into the realm of what an older Derrida called the related realms of politics and friendship (Derrida, 2011). "Politics" counts because no amount of epistemological labour will ever fully justify residual decisions at the heart of a science; "friendship" matters because for us to share and comprehend those activities that lead to the formulation of knowledge requires a mutually acceptable, residual element of trust. If thus we are faced with events that should not matter but which nonetheless throw wide open the door towards questioning, and finally willing neither to use "scale" as a simple extension of a structural logic (by treating "events" as a simple extension of "structure" at a smaller scale), nor to continue to pretend that "private" or "event-filled" languages will provide us with answers (see Wittgenstein, 1953, Sect. 243), what kind of labour can we embrace from here on? Returning to the Derrida of October 1966, we could in- sist that the task set for a progressive journal at the crossroads of different traditions must engage centrally with the art of decentring or dislocating those very same traditions for it not to be held hostage by them. Derrida's description of ethnography as a privileged science holds true no less for the kind of geography we should support through our editorial work:

"One can in fact assume that ethnology could have been born as a science only at the moment when a de-centering had come about: at the moment when European culture - and, in consequence, the history of metaphysics and of its concepts - had been dislocated, driven from its locus, and forced to stop considering itself as the culture of reference. This moment is not first and foremost a moment of philosophical or scientific discourse, it is also a moment which is political, economic, technical, and so forth.” (Derrida, 2001:356)

Acknowledging that geographers are by definition dependent on "difference", the very moment they attempt to construct "a geography" is perhaps a first step along this particular way; practically speaking, this would imply a focus not on translation as a way of constructing bridges between and thus reconciling conceptual régimes but on remaining open, exploring and critically contextualising the space between traditions instead. Of course, any such act of dislocation is tied up with that which it seeks to dislocate, but given that in our case this "that" is already a plural "that", we could regard this dependency as fortuitous. To quote once again from "Structure, Sign and Play":

"The quality and the fecundity of a discourse are perhaps measured by the critical rigor with which this relationship to the history of metaphysics and to inherited concepts is thought. Here it is a question of a critical relationship to the language of the human sciences and a question of a critical responsibility of the discourse. It is a question of putting expressly and systematically the problem of a discourse which borrows from a heritage the resources necessary of that heritage itself. A problem of economy and strategy." (Derrida, 2001:356-357)

We may call the result a "translation without finality", a materially resonating invitation to keep going or simply refer to it as a particularly unproductive form of labour - either way, what is crucially important is not to allow any resulting form or knowledge to acquire a trace of naturalness. In other words, editorial work after Derrida must be work that fully embraces the conflictual character of the labour and results that materialises on the printed page of a journal. This "work", this "labour" must remain "strange" - in the sense developed more fully in Ash Amin's book The Land of Strangers (2012): even if we acknowledge that the event that 
is strange or foreign to our structural concepts or practices is always at least partly constitutive of our ideas, we should neither domesticate nor exclude it but invite open dispute around that which is different. Amin uses the term "curatorship" for this labour, which could be a helpful term for what editorship and related tasks should entail: the keeping open of "zones of engagement" (Amin, 2012:8) that invite disagreement. Making this latter visible is what journals ought to be about, while retaining an anchor in concrete, focussed and shared work practices. In this respect, novel practices emanating from newly formed journals like Dialogues in Human Geography (founded in 2011) are instructive, where longer statement papers are followed by several commentaries and a reply by the original author(s). A similarly "excessive" (see Doel, 2009) use of space, friendship and politics could be encouraged on the side of the editorial board, again in the interest of de-naturalising and thereby re-conflictualising the process of knowledge production. Making labour and rendering disagreement visible, rather than subsuming them into invisible procedures like peer-review processes, would seem to be an adequate response to the challenges posed. It would also chart a way forward, away from predictable continuations and scalings all the while retaining - through the creation of a dialogical "commons" - an interest in those compromises that afflict both structure and event.

Acknowledgements. The author would like to thank the editorial team for their encouragement and all the participants of the 2012 GH symposium devoted to discussing a future for the journal for their helpful comments.

Edited by: B. Korf

Reviewed by: two anonymous referees

\section{References}

Abler, R., Adams, J., and Gould, P.: Spatial Organization. The Geographer's View of the World, Englewood Cliffs, NJ, Prentice Hall, 1972.

Amin, A.: The Land of Strangers, Cambridge, Polity, 2012.

Anderson, B.: Becoming and being hopeful: towards a theory of affect, Environ. Plann. D, 24, 733-52, 2006.

Anderson, B. and Wylie, J.: On geography and materiality, Environ. Plann. A, 41, 318-335, 2009.

Barnes, T.: Lives lived and lives told: biographies of geography's quantitative revolution, Environ. Plann. D, 19, 409-429, 2001.

Barnes, T.: Placing ideas: genius loci, heterotopia and geography's quantitative revolution, Prog. Hum. Geog., 28, 565-595, 2004.

Barnes, T.: "Not only... but also": Quantitative and Critical Geography, Prof. Geogr., 61, 292-300, 2009.

Barnes, T. and Hannah, M.: The place of numbers: histories, geographies, and theories of quantification, Environ. Plann. D, 19, 379-383, 2001.

Berry, B. and Garrison, W.: The functional bases of the central place hierarchy, Econ. Geogr., 34, 145-154, 1958.
Bunge, W.: Fred K Schaeffer and the science of geography, Ann. Assoc. Am. Geogr., 69, 128-132, 1979.

Chorley, R. and Haggett, P. (Eds.): Integrated Models in Geography, Part IV of Models in Geography, London, Methuen, 1969.

Christaller, W.: Central Places in Southern Germany, trans. C. Baskin, Englewood Cliffs, NJ, Prentice Hall, 1966.

Derrida, J.: Structure, sign, and play in the discourse of the human Sciences, Writing and Difference, trans. A Bass, Chicago, University of Chicago Press, 351-370, 2001.

Derrida, J.: The book to come, Paper machine, trans. R Bowlby, Stanford, Stanford University Press, 4-18, 2005.

Derrida, J.: Politique et amitié, Paris, Galilée, 2011.

Dewsbury, J.-D.: Language and the event: the unthought of appearing words, in: Taking-Place: Non-representational theories and geography, edited by: Anderson, B. and Harrison, P., Farnham, Ashgate, 147-160, 2010.

Dixon, D. P. and Jones III, J. P.: My dinner with Derrida, or spatial analysis and poststructuralism do lunch, Environ. Plann. A, 30, 247-260, 1998.

Doel, M.: 1a. Qualified quantitative geography, Environ. Plann. D, 19, 555-572, 2001.

Doel, M.: Guest editorial. Just excess. The joy of waste, Environ. Plann. D, 27, 956-965, 2009.

Doel, M. A.: A hundred thousand lines of flight: a machinic introduction to the nomad thought and scrumpled geography of Gilles Deleuze and Félix Guattari, Environ. Plann. D, 14, 421439, 1996.

Flowerdew, R.: Reacting to Ground Truth, Environ. Plann. A, 30, 289-301, 1998.

Garrison, W.: Applicability of statistical inference to geographical research, Geogr. Rev., 46, 427-429, 1956.

Gould, P.: Methodological developments since the fifties, Progress in Geography, 1, 1-49, 1969.

Gould, P.: Becoming a Geographer, Syracuse, Syracuse University Press, 1999.

Haggett, P. Geography: a modern synthesis, London, Harper and Row, 1972.

Hägerstrand, T.: Innovation diffusion as a spatial process, trans A Pred, Chicago, University of Chicago Press, 1967.

Hannah, M.: Sampling and the politics of representation in US Census 2000, Environ. Plann. D, 19, 515-534, 2001.

Hannah, M.: Dark territory in the information age: learning from the West German Census Boycotts of the 1980s, Farnham, Surrey, Ashgate, 2010.

Hannah, M. and Strohmayer, U.: Ornamentalism. Geography, Language, and the Autonomy of the Subject in Structuration Theory, Environ. Plann. D, 9, 309-327, 1991.

Harvey, D.: Social justice and the city, London, Arnold, 1973.

Harris, C.: English as international language in geography: development and limitations, Geogr. Rev., 91, 675-689, 2010.

Heidegger, M.: Sein und Zeit, Tübingen, Niemeyer, 1927.

Heidegger, M.: Über den Humanismus, Frankfurt am Main, Klostermann, 1949.

Heidegger, M.: An Introduction to Metaphysics, New Haven, Yale University Press, 1959.

Jones III, J. P., Woodward, K., and Marston, S.: Situating flatness, Transactions of the Institute of British Geographers, NS, 32, 264-276, 2007. 
Jones, M.: Phase space: geography, relational thinking and beyond, Prog. Hum. Geog., 33, 487-506, 2009.

Kwan, M.-P. and Schwanen, T.: Quantitative Revolution 2: The Critical (Re)Turn, Prof. Geogr., 61, 283-291, 2009.

Lévi-Strauss, C.: Structural Anthropology, New York, Doubleday, 1963.

Livingstone, D.: The geographical tradition, Oxford, Blackwell, 1992.

Marchand, B.: Quantitative geography: revolution or counterrevolution?, Geoforum, 5, 15-23, 1974.

Marston, S., Jones III, J. P., and Woodward, K.: Human Geography without scale, Transactions of the Institute of British Geographers, NS, 30, 416-432, 2005.

Olsson, G.: Birds in Egg/Eggs in Bird, London, Pion, 1980.

Olsson, G.: Lines of Power/Limits of Language, Mineapolis, University of Minnesota Press, 1991.

Philo, C. with Mitchell, R., and More, A.: Guest editorial, Environ. Plann. A, 30, 191-201, 1998.

Pickles, J. (Ed.): Ground Truth, New York, Guilford, 1995.

Schaeffer, F.: Exceptionalism in Geography: a methodological examination, Ann.e Assoc. Am. Geogr., 43, 226-249, 1953.

Sheppard, E.: Quantitative geography: representations, practices, and possibilities, Environ. Plann. D, 19, 535-554, 2001.

Strohmayer, U.: The event of space. Geographic allusions in the phenomenological tradition, Environ. Plann. D, 16, 105-121, 1998.
Strohmayer, U. and Gould, P.: L'evolution de la pensee geographique au 20e siècle, Geographie Economie Societé, 5, 130, 2003

Taylor, P.: Quantitative methods in geography: an introduction to spatial analysis, Boston, Houghton Mifflin, 1977.

Thrift, N.: Non-representational theory. Space, politics, affect, Abingdon, Oxon, Routledge, 2007.

Wardenga, U.: German geographical thought and the development of Länderkunde, Inforgeo, 18/19, 135-155, 2006.

Whatmore, S.: Hybrid Geographies. Natures, cultures, spaces, London, Sage, 2002.

Wilson, A. G.: Mathematical models and geographical theory, in: Horizons in Human Geography,, edited by: Gregory, G. and Walford, R., London, Macmillan, 29-47, 1989.

Wittgenstein, L.: Philosophical Investigations, trans G. E. M. Anscombe, Oxford, Blackwell, 1953.

Woodward, K.: Events, spontaneity and abrupt conditions, in: Taking-Place: Non-representational theories and geography, edited by: Anderson, B. and Harrison, P., Farnham, Ashgate, 321-340, 2010

Wyly, E.: Strategic Positivism, Prof. Geogr., 61, 310-322, 2009. 